\title{
Development of a New Quantile-Based Method for the Assessment of Regional Water Resources in a Highly-Regulated River Basin
}

\author{
Salam A. Abbas ${ }^{1} \cdot$ Yunqing Xuan ${ }^{1}$ (D) \\ Received: 11 September 2017 / Accepted: 19 May 2019 / \\ Published online: 10 June 2019 \\ (C) The Author(s) 2019
}

\begin{abstract}
In this paper, we present a study of assessing regional water resources in a highly regulated river basin, the Dee river basin in the UK. The aims of this study include: 1) to address the issue of hydrological simulations for regulated river catchments; 2) to develop a new method revealing the trends of water resources for different scenarios (e.g. dry and wet) and 3) to facilitate water resources assessment under both climate change impacts and regulations. We use the SWAT model to model the hydrological process of the river basin with carefully designed configurations to isolate the impact from the water use regulations and practice. The spatially-distributed model simulations are then analysed with the quantile regression method to reveal the spatial and temporal patterns of regional water resources. The results show that this approach excels in presenting distributed, spatially focused trend information for extremely dry and wet scenarios, which can well address the needs of practitioners and decisionmakers in dealing with long-term planning and climate change impact. The representation of the management practice in the modelling process helps identify the impact from both climate change and necessary regulatory practices, and as such lays a foundation for further study on how various management practices can mitigate the impact from other sources such as those from climate change. The novelty of the study lies in three aspects: 1) it devises a new way of isolating and representing management practice in the hydrological modelling process for regulated river basins; 2) it integrates the QR technique to study spatial-temporal trends of catchment water yield in a distributed fashion, for wet and dry scenarios instead of the mean; 3 ) the combination of the methods are able to reveal the impacts from various sources as well as their interactions with catchment water resources.
\end{abstract}

Keywords Regulated river basins $\cdot$ SWAT - Quantile regression $\cdot$ Climate change impact $\cdot$ Natural flow restoration

Yunqing Xuan

y.xuan@swansea.ac.uk

1 College of Engineering, Swansea University Bay Campus, Swansea SA1 8EN, UK 


\section{Introduction}

Climate change impact on water-related issues such as floods and droughts has been an active research area thanks to the fact that those physical phenomena and their variations are easily and directly perceived (Solomon 2007). There have been plenty of studies on climate change impact at the river basin level, many of which share a key feature, that is the use of hydrological models driven by long-term historical forcing fields (such as precipitation) or climate projections for future scenarios, e.g. Abbaspour et al. (2009) and Ficklin et al. (2013). More recently, researchers are paying more attention to the uncertainties and biases in such projection driven hydrological simulations (Cannon et al. 2015; Miao et al. 2016).

Human activities have intensely affected water cycle across the world, especially at the watershed scale (Yang et al. 2014). Water management considerably changes natural streamflow regimes via modifying retention time and water exchanges among various components of the water cycle (Haddeland et al. 2007). Hydrological consequences of management activities should be explicitly examined for effective water resource planning and management (Siebert et al. 2010), particularly for catchments striving to maintain sustainable water supply for multiple stockholders. The accurate simulation of the water cycle in highlyregulated watersheds faces challenges in reliably identifying the effects of management practices (e.g., reservoir operations) on the hydrological cycle (Wada et al. 2017).

Construction of reservoirs and dams has significant impacts on the amount and variability of downstream streamflow (Vicente-Serrano et al. 2017). For instance, reservoir operations reduced (9-25) \% of summer runoff to the Pacific Ocean in western U.S. and Mexico (Haddeland et al. 2007). However, it is still not explicitly examined how water management practices can potentially change the hydrological responses for the high flow condition (flooding) and low flow (drought).

Many models are developed to simulate hydrological effects and watershed-scale processes of various management scenarios. Watershed models are powerful tools for examining the complex nature of those processes that influence surface and groundwater hydrology in watersheds (Singh et al. 2005). A watershed model can be utilised for better understanding the impact of different management practices on these hydrological processes. Recently, semiand fully-distributed hydrological models have gained more applications owing to the increased availability of spatial data. Choosing suitable models to simulate the hydrological processes of a specific watershed has continuously been a challenging task.

Trend analysis has also been a helpful practice to revealing patterns of changes in hydrological processes. Such analysis usually is carried out over either historical observations such as precipitation and temperature, to assess whether there are significant trends and to identify the possible causes of those changes; or in conjunction with the use of projection-driven hydrological simulations to manifest future trend (Arnell 2004; Schneider et al. 2013; Piao et al. 2007).

In this respect, non-parametric statistical methods are preferred by many over parametric one (Sonali and Kumar, 2013) as they are less susceptible to outliers and need no assumption of predefined distribution or homogeneity. The non-parametric Mann-Kendall (MK) test (Mann 1945; Kendall 1975) has been frequently used to quantify the significance of trends in precipitation time series (Modarres and Sarhadi 2009; Tabari et al. 2011). The original Mann-Kendall test does not reveal the magnitude of the trend, which has been complemented by the Theil-Sen slope technique (Sayemuzzaman and Jha 2014). This approach gives a more robust estimation of the slope than the least square methods as it is insensitive to extreme values and outliers (Breidt 2005). 
When it comes to water resources management at the catchment level, the above-mentioned approaches, e.g. hydrological simulations alongside a trend analysis of the simulated, aggregated values, become increasingly insufficient and difficult to meet the demand for more finegranulated information to assess climate change impacts. This is manifested as follows.

Firstly, many catchments already have management and regulations in place. Modelling the hydrology of those catchments is apparently a challenging process, let alone representing the impact from climate change. Many previously reported studies of climate change impact on general flow trends are largely conducted on those 'natural' catchments such as Schneider et al. (2013); the literature of those applied to highly-regulated river basins are scarce. There are some attempts, such as Dutta et al. (2015), Yoon et al. (2016); which mainly focused however on the modelling procedure per se, whereas, yet to address separating anthropogenic impacts from climate change.

Secondly, the general trend analysis of aggregated values is not as useful for catchment level water resources management that usually needs specific information about extreme scenarios, e.g., floods and droughts. To a certain extent, this problem can be addressed by stratifying the data into different categories. However, this may also reduce the sample size hence the information of variability.

In this paper, we present a new method that integrates hydrological modelling of a highlymanaged river basin with the quantile regression $(\mathrm{QR})$ technique for analysing distributed trends of flow and water yields over the basin for both dry (potential droughts) and wet (potential flooding) conditions. A semi-distributed hydrological model, the Soil Water Assessment Tool (SWAT) (Arnold et al. 1998) cares to simulate the distribution of water yields and its spatio-temporal variation. The approach taken by this study to represent river flow regulation, water use and abstraction in the modelling process makes it distinctive from others. In addition, it addresses the trend of more extreme values (e.g. dry and flooding conditions) by making use of the linear quantile regression method (QR) (Koenker and Bassett 1978; Koenker 2005).

The QR method was initially developed for regression analysis in econometrics as an alternative and arguably better tool to the ordinary least square method (OLS). It has since been used in many other disciplines (Tareghian and Rasmussen 2013). The method has received considerable attention in many statistical literatures, but less so in areas related to water resources analysis (Tareghian and Rasmussen 2013). Several studies are reported in generic environmental sciences including analysis of streamflow distributions (Luce and Holden 2009); studying rainfall trend (Mazvimavi 2010); hydrological uncertainty (Weerts et al. 2010); and hydro-metrological analysis (Villarini et al. 2011). In climatology, the QR method has been used to downscale precipitation data such as Tareghian and Rasmussen (2013).

The QR technique is a powerful extension to the ordinary linear regression in a sense that the quantiles of given response variables are conditioned on the independent variables. As summarised by Koenker (2005), it offers several advantages and benefits which are discussed in detail in the Methodology section.

The rest of this paper is structured as follows: the next section introduces the study area as well as the data obtained for this study, followed by the section of methodology that discusses the details of the model set up, scenario building and the approach of applying the QR analysis. The results are then discussed and the conclusions and recommendations are given in the end.

\section{Study Area}

The Dee river originates from the mountainous area of Snowdonia National Park in North Wales in the United Kingdom. The mainstream of the river is $113 \mathrm{~km}$ long with a catchment 
area of $2,215 \mathrm{~km}^{2}$ as shown in Fig. 1. It flows eastward to the Wales-England border at the City of Chester before discharging into the Irish Sea at the Liverpool Bay. The annual precipitation over the river basin shows a clear west-east declining trend with $1,700 \mathrm{~mm}$ in the western part quickly reducing to $685 \mathrm{~mm}$ in the east where flat, lowland dominates as revealed in Fig. 2. The temporal distribution of the annual precipitation demonstrates a strong seasonal pattern with wet winters (178-578) $\mathrm{mm}$ in December, January and February and normally dry summers (165-278 mm) in June, July and August.

The study area has a moderate climate which is similar to the rest of the UK but can also be slightly unpredictable at times. The mean annual temperature at low altitudes varies from about $9.5^{\circ} \mathrm{C}$ to $11{ }^{\circ} \mathrm{C}$, with the higher values occurring around or near to the coasts. The mean annual temperature decreases by approximately $0.5^{\circ} \mathrm{C}$ for each $100 \mathrm{~m}$ increase in height (BADC 2015).

The middle and downstream of the basin are subjected to groundwater management regulations through the licensed pumping wells for public water supply (PWS) and agricultural water uses (DEFRA 2014). The average depth of the groundwater table is around $2 \mathrm{~m}$ at the downstream of the Dee River basin; and it can reach $100 \mathrm{~m}$ in the mountainous region of the upstream of the river basin (McKenzie 2015). In winter, frequent and abundant precipitation leads to significant fluctuations in the groundwater level. However, summers often see the groundwater level fluctuate within a narrow range due to low rainfall.

Records show that the storms and subsequent flooding in the winter of 2013/2014 had a significant impact on some communities, businesses, infrastructure and the environment. There could be more extremes in the weather with a changing climate leading to more frequent

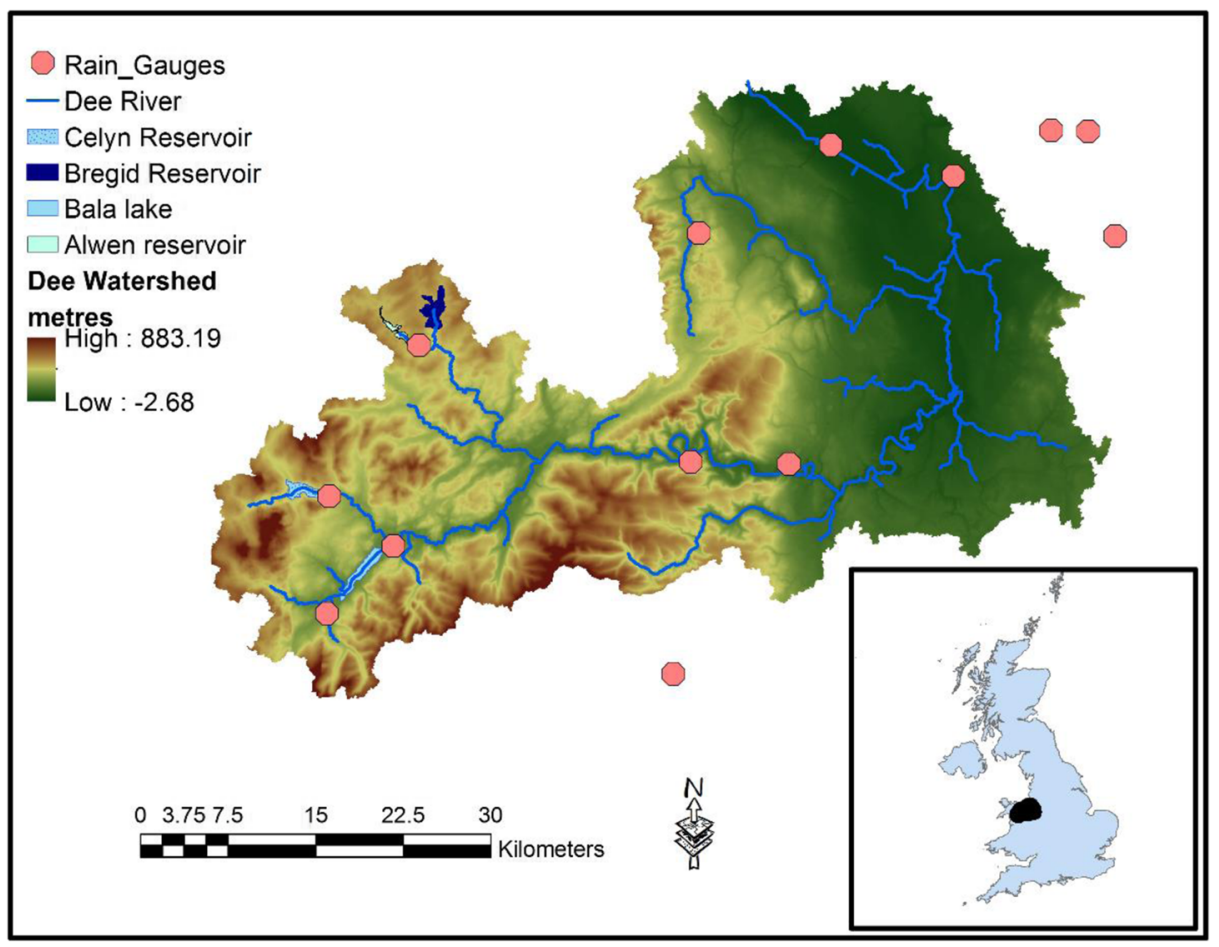

Fig. 1 The Dee river catchment 


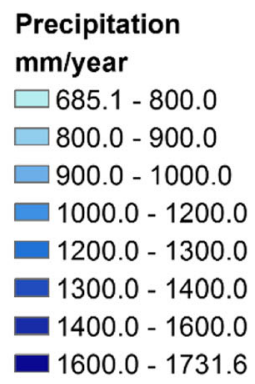

Fig. 2 Annual precipitation distribution in the Dee river catchment

and more severe flooding (Natural Resources Wales and Environmental Agency 2014). Additionally, the droughts in 1995 and 1996 are the most notable drought events of the Dee River basin (Mayall 2000).

According to the Natural Resources Wales (2015), the Dee River basin is an exemplary case for its advanced river basin management that is mainly achieved by:

1. regulating the upstream river flow by controlling the release of water from the four main reservoirs: Celyn, Brinig, Bala and Alwen;

2. sustaining substantial surface water withdraws by adjusting reservoir release in summer in the middle and downstream for industrial and public water supply; and

3. reducing flood risks in the middle and downstream during wet seasons.

Overall, the management of the river basin is aimed at maintaining industrial and domestic water supply for the regions of Wirral, Cheshire, Shropshire and North-East Wales, as well as effectively reducing the flood risks in the downstream urban area (Natural Resources Wales and Environmental Agency 2014).

The surface water abstractions from the river for PWS are governed by the River Dee General Directions which set out rules for abstraction during drought conditions and are approved by the statutory Dee Consultative Committee (DEFRA 2014). If the storage in the regulating reservoirs falls to the drought action trigger level, a meeting of the Committee will be sought to discuss the introduction of drought alleviation measures as enshrined in the Dee General Directions. 
The river flows are regulated by the River Dee regulation scheme which comprises a system of flow balancing along the river. The four major lakes/reservoirs in the upstream: the Bala Lake, the Celyn reservoir, the Brenig Reservoir and the Alwen Reservoir are operated primarily as water supply reservoirs by Welsh Water (DEFRA 2014).

The River Dee Regulation Scheme utilises the storage in the Celyn reservoir, the Brenig reservoir, and the Bala Lake to ensure that up to $733 \mathrm{Ml} /$ day can be abstracted in the lower reaches for PWS. In terms of a hierarchy of the use of the water from the reservoirs, the release order of water is (DEFRA 2014): Bala Lake first followed by the Celyn Reservoir and finally the Brenig Reservoir.

\section{Data}

Three types of data are collected in this study, namely (1) the static dataset, such as the DEM, soil type data and land use that are assumed to be static over the study period; (2) the historical observations of precipitation and the river flow data, as well as the temperature data; (3) the operational data of flow regulation and water abstraction data that represent management practice. Most data used are available in the public domain except those requested from the water management authority that are subjected to an academic license. The data collected are summarised in Table 1. The only information about the surface and groundwater abstractions is the maximum daily license withdraws in $\mathrm{m}^{3} /$ day.

Data screening and correction have been conducted on the precipitation from rain gauges and the streamflow data from river gauge stations before carrying on data analysis. The screening involves checking raw data, recognising outliers and filling missing data. The precipitation and streamflow data have been subjected to rigorous quality control by the British Atmospheric Data Centre (BADC), the Met Office and Centre for Ecology and Hydrology respectively.

\section{Methodology}

The main challenges in assessing water resources in highly regulated catchments are due to the fact that the observed data are not a direct reflection of the basin's hydrological processes. It is necessary to 'restore' the data to represent the 'natural' state of the river basin by carefully isolating the river flow regulations and water abstractions from the true rainfall-runoff process. Therefore, our main methodology comprises of the following steps:

1) designing two scenarios of river basin delineation to isolate the flow regulations and restore the 'natural' flow by modelling the water abstraction practice;

2) using a semi-distributed hydrological model SWAT to model the two scenarios and obtain the flow and water yield simulations under the conditions with and without management interventions; and

3) applying the quantile regression method to reveal the trends and their distributions with regard to the two prescribed quantiles representing both wet and dry conditions. 


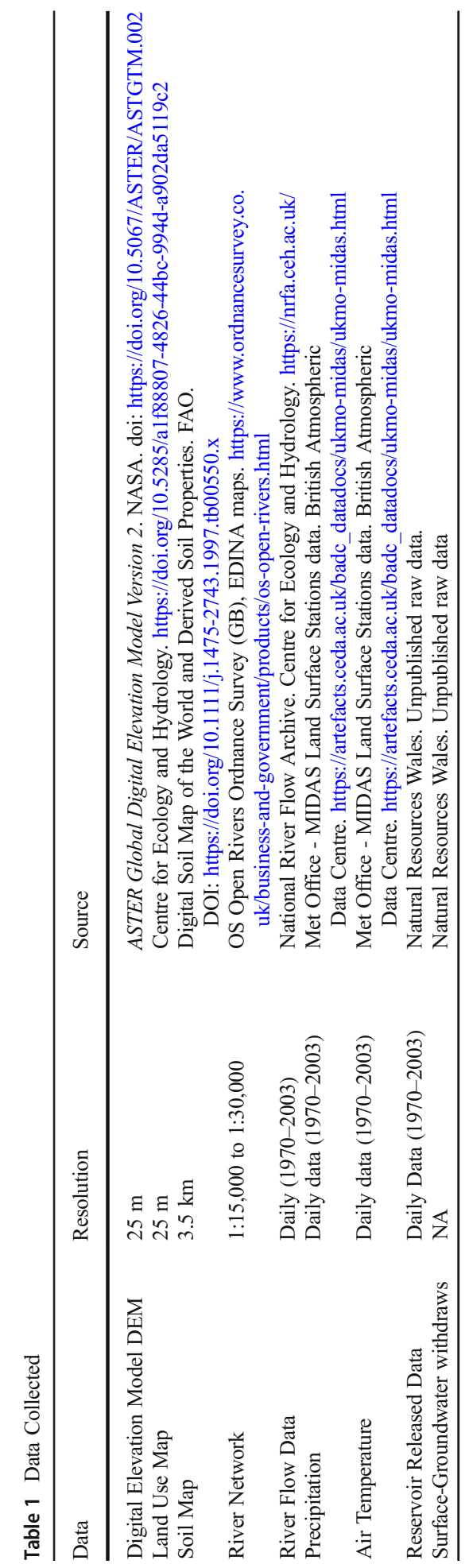




\subsection{Flow Regulation and Water Abstraction Interaction}

The observed river flow data are in fact the result of the natural flow process regulated by the management rules which in turn are based upon the estimate of probable water use in the main water withdraw area. For the Dee catchment, releases from the four upstream reservoirs contribute substantially to the river flow; for instance, the catchment area above Chester Weir is $1,816 \mathrm{~km}^{2}$ with an average natural runoff of $36.8 \mathrm{~m}^{3} / \mathrm{s}(639 \mathrm{~mm} /$ year $)$ and $16 \%$ of the area and $33 \%$ of this runoff are controlled by the regulating reservoirs (DEFRA 2014).

There are circa 30 PWS licences with significant abstractions in the area. In 2009, the PWS abstracted a total of 197,042 Ml which accounted for approximately 93\% of all the water abstracted in the Dee Catchment Abstraction Management Strategy (CAM) area, only around $1 \%$ of which was taken from groundwater sources (DEFRA 2014). The locations of these PWS licenses are shown in Fig. 3. Although the capacity metric of the water abstraction points along with their locations are known, the real-time water abstraction amounts are unavailable. According to the management practice, reservoir releases are determined by the planned water abstraction on the day; therefore we are able to use the following procedure to inversely represent the day water abstraction at each PWS site.

To conserve water supplies and ensure efficiency of operation, the PWS companies provide a weekly abstraction forecast to Natural Resources Wales to estimate the required releases from the reservoirs (DEFRA 2014). An inversion of this procedure is used to estimate the daily

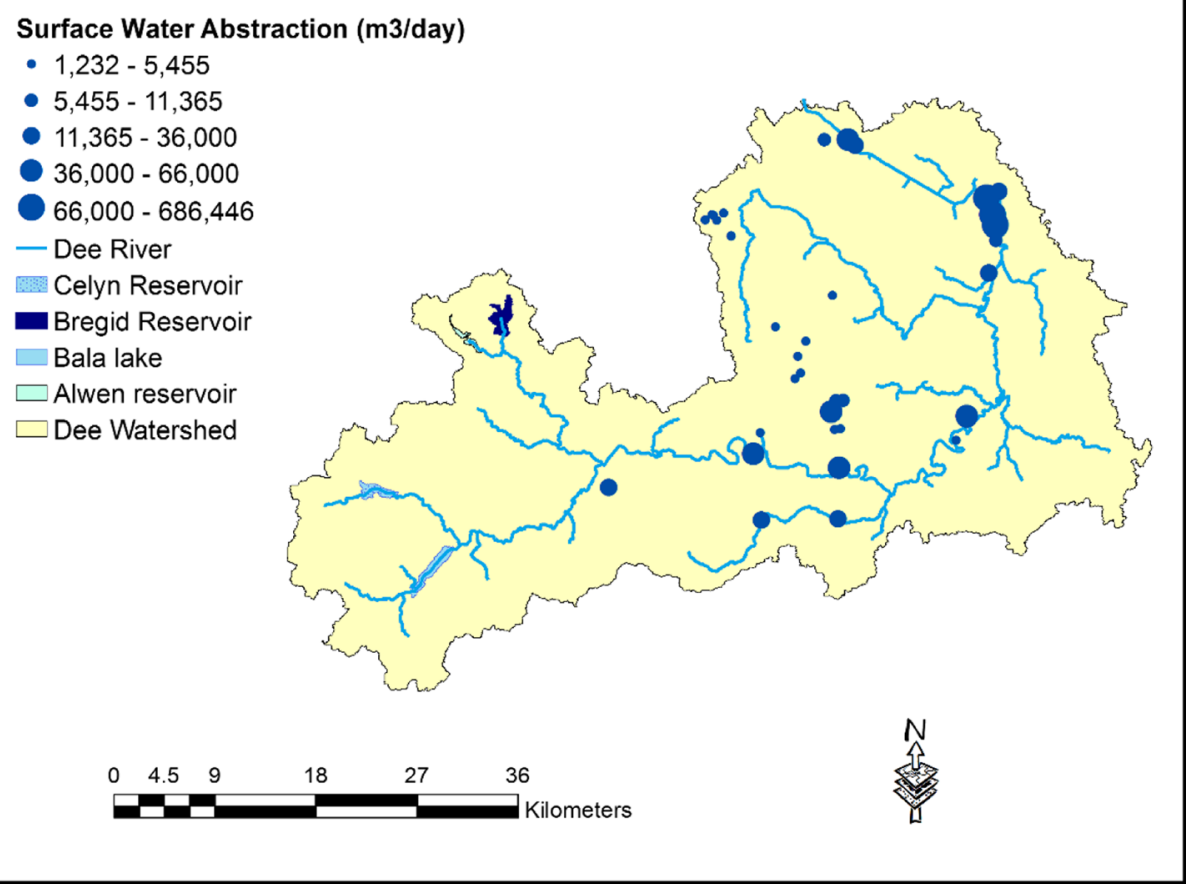

Fig. 3 Significant water abstraction points in the Dee catchment 
water withdrawal amount at the water abstraction points. The $i^{\text {th }}$ day water withdrawal at an abstraction point $k$, denoted as $W_{i, k}$ can be estimated as:

$$
W_{i, k}=\mathrm{CNR}_{i} \times M D L A_{k}
$$

where $\mathrm{CNR}_{i}$ is the coefficient of the normalised reservoir release on the $i$ th day, and MDLA $k$ refers to the Maximum Daily Licensed Abstraction at point $k$. The normalised reservoir release from the three reservoirs $\mathrm{NR}_{i, j}, j=1,2,3$ is calculated by nomarlising the $i^{\text {th }}$ day release over the span between the minimum and maximum releases over the entire period of simulation, i.e. 1970-2004:

$$
N R_{i, j}=\frac{R_{i, j}-M I N R_{j}}{M A X R_{j}-M I N R_{j}}, j=1,2,3
$$

The coefficient is then calculated by summing up the three normalised releases:

$$
\mathrm{CNR}_{i}=\sum_{j=1}^{3} N R_{i, j}
$$

It is possible that a $\mathrm{CNR}_{i}$ may exceed 1 in which case the value is capped to 1 . The main reason for aggregating reservoir releases is due to a hierarchy of releasing water from the reservoirs. Following the procedure above, a 'restored' daily flow time series is produced and ready for the subsequent modelling purposes. Understandably, although this method helps to represent the interaction between flow regulation and water abstraction, it also brings in uncertainties. It can be further improved by probabilistically modelling the water abstraction conditional on other variables such as temperature.

\subsection{Hydrological Modelling Using SWAT}

The SWAT is a public domain hydrological model which has been tested in many applications in different parts of the world. It is a continuous, basin-scale and parameter-distributed model, designed to simulate the rainfall-runoff process under various spatial and temporal scales. Being a quasi-distributed model, SWAT makes use of hydrological response units (HRUs) to describe the spatial distribution of soil characteristics, land use, topography within a catchment.

The calculations in SWAT are performed for each HRU and then scaled up to the sub-basin outlets according to the area of the HRU as a fraction of the sub-basin. This results in the HRUs lacking spatial relations that are typically seen in a fully-distributed model but yield a computationally efficient calculation scheme allowing for rapid watershed simulation over long time periods (Bailey et al. 2016).

The division of the watershed enables the model to reflect differences in evapotranspiration for different soil and crops. Runoff is calculated separately for each HRU and routed to obtain the total runoff for the watershed (Neitsch et al. 2011). Figure 4 shows a schematic representation of the conceptual water balance of the SWAT model. It is of particular interest to note that in the land phase, SWAT simulates the hydrological cycle based on the water balance equation (Neitsch et al. 2011) as follows:

$$
S W_{t}=S W_{o}+\sum_{i=1}^{t}\left(R_{\text {day }}-Q_{\text {surf }}-E_{a}-W_{\text {seep }}-Q_{g w}\right)_{i}
$$




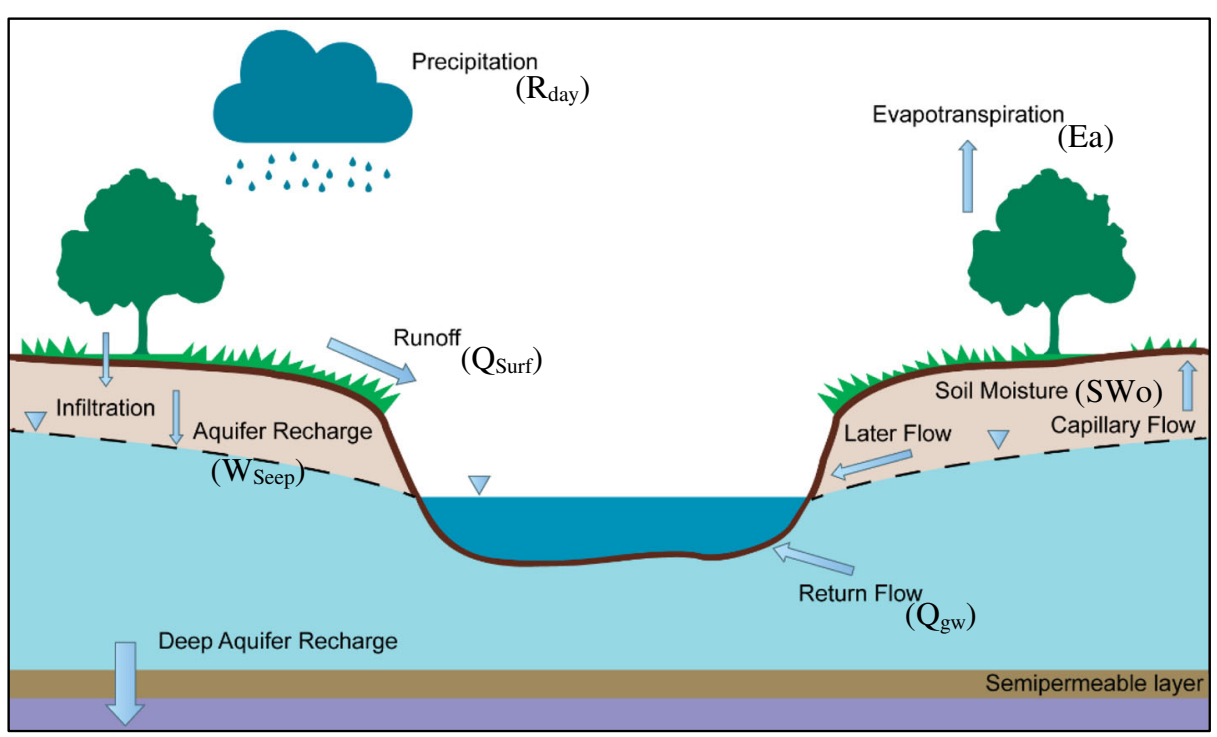

Fig. 4 Schematic representation of conceptual water balance of the SWAT model

where:

$S W_{t} \quad$ final soil water content $(\mathrm{mm})$,

$S W_{o} \quad$ initial soil water content on day $i(\mathrm{~mm})$,

$t$ time in (days),

$R_{\text {day }} \quad$ the amount of precipitation on day $i(\mathrm{~mm})$,

$Q_{\text {surf }}$ the amount of surface runoff on day $i(\mathrm{~mm})$,

$E_{a} \quad$ the amount of evapotranspiration on day $i(\mathrm{~mm})$,

$W_{\text {seep }}$ the amount of water entering the vadose zone from soil profile on day $i(\mathrm{~mm})$,

$Q_{g w} \quad$ the amount of return flow on day $i(\mathrm{~mm})$.

The surface runoff $Q_{\text {surf }}$ is predicted for daily rainfall using SCS curve number equation (USDA-SCS 1972) as:

$$
\begin{gathered}
Q_{\text {surf }}=\frac{(R-0.2 s)^{2}}{R+0.8 s}, R>0.2 s \\
Q_{\text {surf }}=0.0, R \leq 0.2 \mathrm{~s}
\end{gathered}
$$

where $s$ is a retention parameter which is related to the curve number $C N$ in the following equation:

$$
s=254\left(\frac{100}{C N}-1\right)
$$

To measure the impact of management practice, the entire river basin is modelled with two different configurations: Scenario I and II which differ by their objectives as well as by the areas they represent. Considering data availability, the entire catchment of Dee is separated into three parts (Fig. 5). The two upper-stream sub-catchments cover the three water supply 

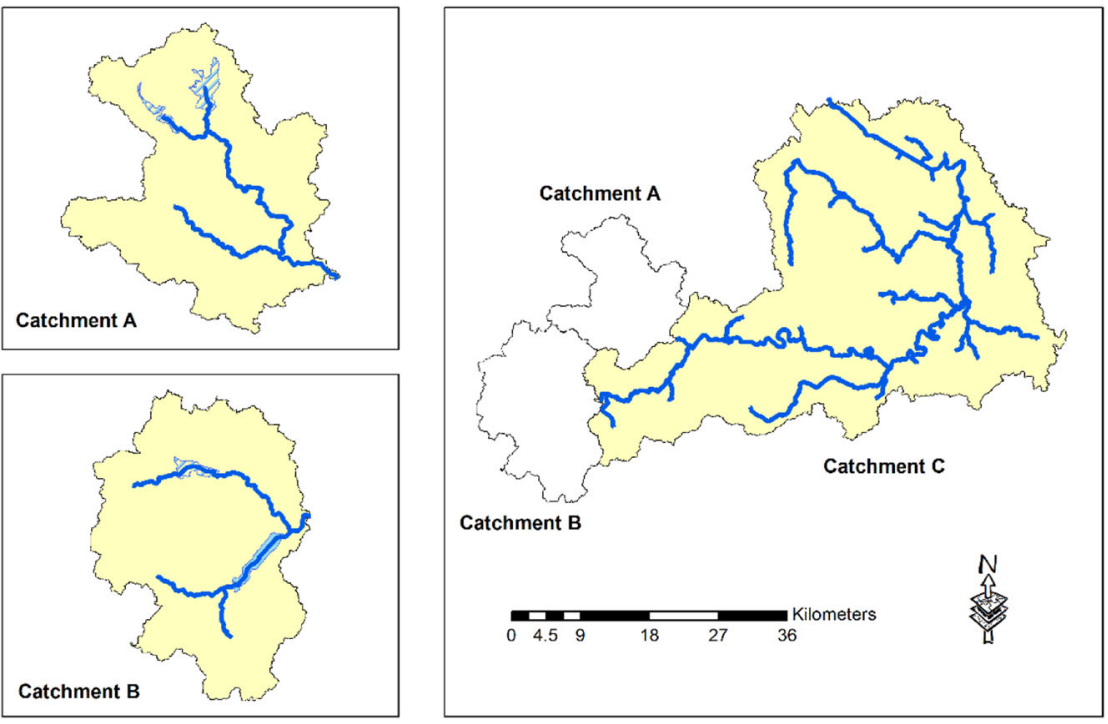

Fig. 5 Delineation of the sub-catchments in the upstream of Dee river

reservoirs whose releases are measured at the two inlets to sub-catchment $\mathrm{C}$ which constitutes the main study area. Correspondingly, there are three SWAT models set up for sub-catchments A, B and C, namely models A, B and C.

The first scenario focuses on the so-called 'real-life' situation, i.e. to model the catchment as it is. In this setting, the observed flow at the outlets of both sub-catchments A and B (also the two inlets to sub-catchment C) are used to build Model $\mathrm{C}$ alongside other historical datasets. The daily water abstractions at the PWS sites are estimated using the method presented previously. Neither sub-catchment in the upper stream is modelled. In other words, scenario I takes reservoir releases as the known boundary conditions to study the impact of water management practice in the main part of the catchment under current regulation.

The second scenario takes a different stand, aiming to reveal the 'natural state' of the catchment by modelling not only the sub-catchment $\mathrm{C}$ but also both sub-catchments in the upper streams. In this scenario, all reservoirs in the upper streams are modelled as natural lakes with no flow control imposed. The same model $\mathrm{C}$ built in Scenario I is used but instead of being driven by the historical observed flow data at the two inlets, it now takes inputs from the simulated flows from model A and $\mathrm{B}$ at the inlets. The same representation of water abstraction in sub-catchment $\mathrm{C}$ is adopted. In other words, Scenario II is not a 'pure' natural flow simulation as it considers the water abstraction; however, it does offer an insight into the impact of flow regulation.

The three models are calibrated and validated using the Sequential Uncertainty Fitting algorithm, SUFI2 (Abbaspour et al. 2004, 2007). The goodness of fit is quantified using the Nash-Sutcliffe Efficiency Index NSE, Determination Coefficient $\mathrm{R}^{2}$ and Percent of Bias PBIAS as defined by eqs. (8)-(10).

$$
N S E=1-\frac{\sum_{t=1}^{T}\left(Q_{o, t}-Q_{s, t}\right)^{2}}{\sum_{t=1}^{T}\left(Q_{o, t}-\overline{Q_{o}}\right)^{2}}
$$




$$
\begin{gathered}
R^{2}=\left[\frac{\sum_{t=1}^{T}\left(Q_{o, t}-\overline{Q_{o}}\right)\left(Q_{s, t}-\overline{Q_{s}}\right)}{\sum_{t=1}^{T}\left[\left(Q_{o, t}-\overline{Q_{o}}\right)^{2}\right]^{0.5} \sum_{t=1}^{T}\left[\left(Q_{s, t}-\overline{Q_{s}}\right)^{2}\right]^{0.5}}\right]^{2} \\
\text { PBIAS }=\left[\frac{\sum_{t=1}^{T}\left(Q_{s, t}-Q_{o, t}\right)}{\sum_{t=1}^{T} Q_{o, t}}\right] \times 100 \%
\end{gathered}
$$

where $Q_{o, t}$ is the observed flow and $Q_{s, t}$ is the simulated flow at time $t$. It was found in our study that the natural process plays a secondary role; in comparison, the surface water abstractions have a considerable impact on the river flow regime. Historical flow records at the 6 selected river gauge stations are used to measure the performance of model C. For models A and B, the observed flows at the two inlets are used, as revealed in Fig. 6. Table 2 summaries the calibration and validation of the three models.

\subsection{Trend Analysis Using Quantile Regression}

Linear regression has been frequently used to study trends of hydrological variables such as precipitation and river flows, e.g. see Song et al. (2014). One of the major drawbacks of this method is that the trend it manifests is expressed as the mean of variables conditioned on time.

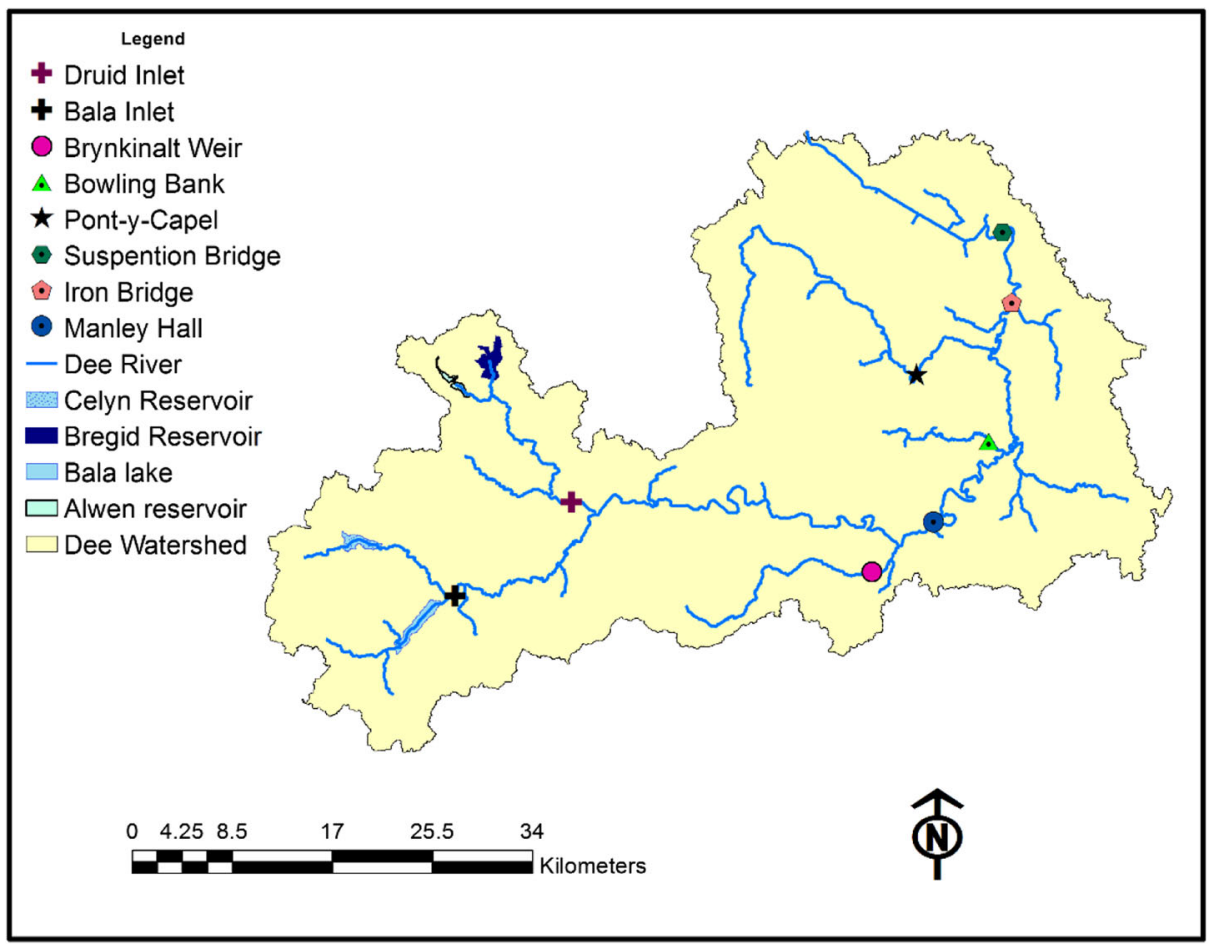

Fig. 6 Locations of the main inlets and the river gauges in Dee River Basin 


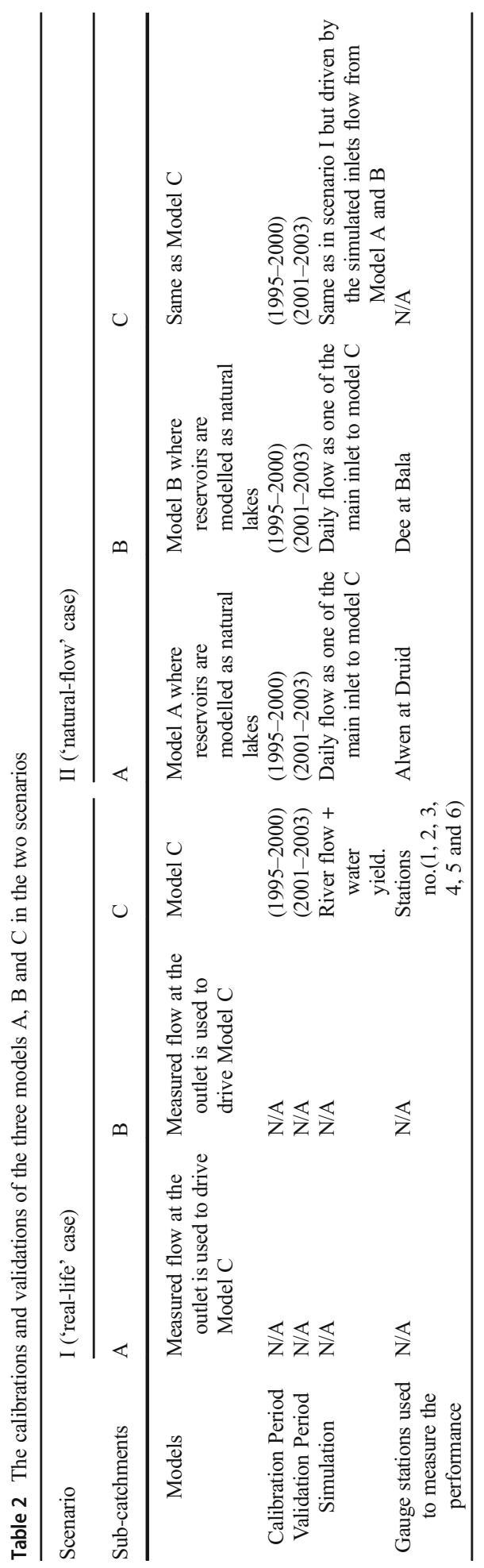


Whilst this can still be very useful in general, it is difficult to gain further insights as to how events associated with more extreme values vary with time.

In contrast, the quantile regression $(\mathrm{QR})$ method sets to model the quantiles of given response variables that are conditioned on the independent variables. As summarised by Koenker (2005), the QR method offers the following benefits:

1. the error terms are not necessary to be normally distributed;

2. it does not assume homoscedastic variables (variables could be heteroscedastic);

3. it is not sensitive to outliers;

4. it can be used to predict a desired quantile of the conditional distribution rather than mean; and

5. it is preferred when the interest is the analysis of distribution rather than average and when the core attention is the tail of distributions.

A quick recap of both methods is presented here. For linear regression-based trend analysis, the river flow time series $Q(t)$ is treated as a random variable that is parametrically modelled as the response to time $t$ with a linear relationship:

$$
Q(t)=\beta_{0}+\beta_{1} t+\epsilon
$$

where $\epsilon$ is the random additive term assumed to be drawn from a normal distribution $N(0, \sigma)$ with a fixed standard deviation $\sigma$ for all $Q(t) ; \beta_{0}$ and $\beta_{1}$ are the intercept and the gradient that can be readily estimated by using the least square method and finally:

$$
\hat{Q}(t)=b_{0}+b_{1} t
$$

where $\hat{Q}(t)$ is the estimated response at time $t$ which in fact is the mean response. $b_{0}$ and $b_{1}$ are estimated intercept and gradient. The estimated gradient is then picked up as the trend indicating how the flow varies with time. The main advantage of using linear regression is due to its simplicity and more importantly because the trend revealed as such can be easily understood (though often misinterpreted) by the general public. The drawbacks of this method are also clear that:

1. the assumptions about the random term $\epsilon$ are not always valid;

2. the use of the mean may not be helpful from the water resources management viewpoint as the latter are more concerned with 'abnormal' such as very wet and dry conditions.

The QR method extends the view by conditioning the quantiles instead of the mean response on the same independent variable. Furthermore, the QR method does not require the assumption of normality nor does it have to be parametric. Like linear regression, the quantile $\tau$ of the flow is (linearly) conditional on time, i.e.

$$
Q_{\tau}(t)=\beta_{0}(\tau)+\beta_{1}(\tau) t
$$

And the coefficients $\beta_{0}(\tau), \beta_{1}(\tau)$ can be estimated using linear programming, such that

$$
\hat{Q}_{\tau}(t)=b_{0}(\tau)+b_{1}(\tau) t
$$


The time dependency (trend) of the given quantile value is revealed by the two linear coefficients. Figure 7 shows an example of different quantile trend lines of a water yield time series from a sub-catchment where a clear spread can be seen. It should be noted that although the above description aims to show how $\mathrm{QR}$ extends the idea of the linear regression, the $\mathrm{QR}$ method does not have to be linear nor parametric. In this study, we choose to use its parametric, linear form to help measure the trends. For quantile regression, bootstrap methods are developed to test the significance of the fit. The analysis in this study is conducted using the R package quantreg (Koenker et al. 2016) which has integrated both the fitting methods as well as the significance test method.

Another advantage of using the QR method is the link between the quantiles and the random events they represent. Undoubtedly, such a relationship is dependent on the underlying probability distribution. For the matter of simplicity, the widely used plotting method can be used to schematically estimate such a link. One of the plotting position formulae is given by Gringorten (1963):

$$
p=\frac{r-0.44}{n+0.12}
$$

where $r$ is the rank of the data and $n$ is the sample size. By using this formula, the higher quantile 0.95 (lower quantile 0.05 ) of the river flow records can be roughly linked to an event of wet condition (dry condition) with a frequency approximately of 1 in 64 years. Such estimate may suffer from small sample size, but nonetheless is able to indicate those 'mildly' extreme events.

In this study, the simulated river flows and water yields at sub-catchments are analysed using the QR method. Understandably, errors in simulations may cause misrepresentation of the trends. To fully address those concerns, it deserves another in-depth study which goes beyond this paper. However, as demonstrated in the subsequent sections, the difference between the trends of simulated flow and those of the observed one are acceptable.

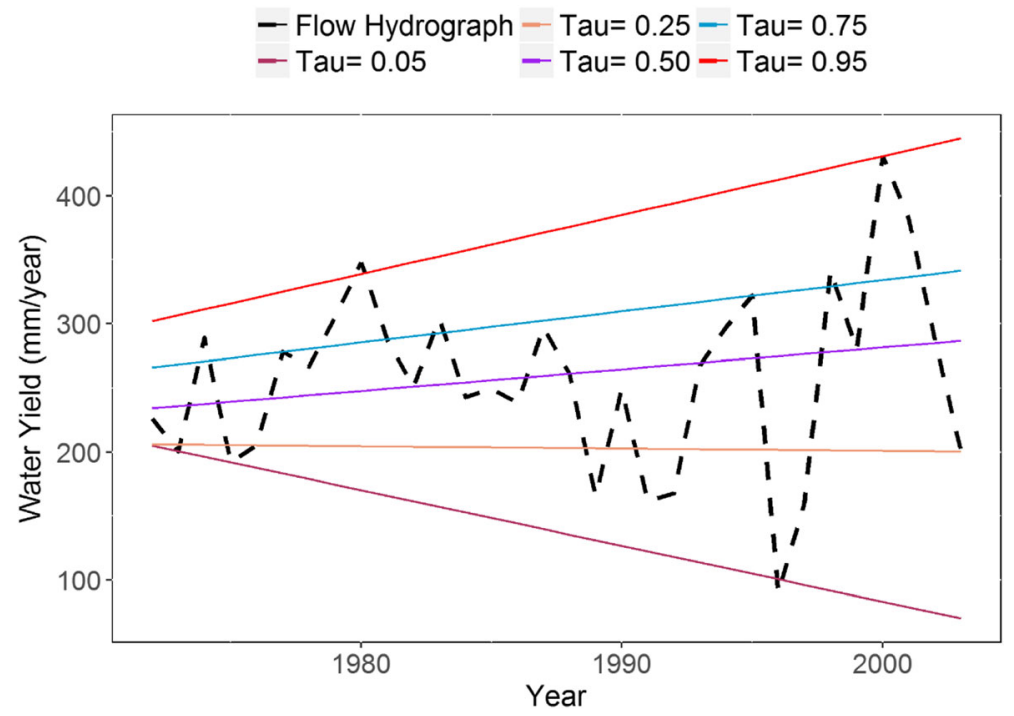

Fig. 7 Various trends of the flow in a downstream sub-basin of the Dee river at different quantiles (indicated by Tau) 


\section{Results and Discussion}

\subsection{Model Simulations}

The comparison between the calibrated stream flow and observations at six locations revealed a good model performance in term of statistical performance indexes $\mathrm{R}^{2}$, NSE and PBIAS as illustrated in Table 3 and Fig. 8. The calibrated model is then used to simulate the entire period from 1970 to 2003 (with a 2-year warming up period).

\subsection{Trend Analysis}

Two approaches are frequently utilised for the trend analysis, among others. The first one is to combine meteorological data into a hydrological model and design several scenarios for the analysis flow regimes. This approach is broadly used for predicting future flow regimes for climate change studies, such as global runoff (Piao et al. 2007). The other approach is to use statistical tests to investigate past trends and qualitatively predict future trends (Kubilius and Melichov 2008).

However, most previous studies of hydrological models have mainly focussed on analysing the mean trend of the hydrological variables (e.g. runoff, blue water, green water, etc.) without considering the impact of management practice on the hydrological variables. Typically, nonparametric methods such as the Mann Kendall test, is used alongside the hydrological models. For instance, Zang and Liu (2013) used the SWAT model to create a hydrological model for the Heihe River basin, China. They used the Mann Kendall trend test to investigate the mean trends of the blue and green water resources for the historical and future periods. Others such as Zhao et al. (2016) also utilised SWAT model and the Mann-Kendall method for examining the spatiotemporal variations of blue and green water resources under different agricultural irrigation expansion and land use change in the Weihe River Basin in China.

There are plenty of studies of trend analysis over observed time series such as river flows, for example, Luce and Holden (2009). The same procedure can certainly be applied in our study, however, it is the use of the semi-distributed hydrological model makes it possible to study the distribution of water resources over space. In this study, instead of investigating the trends of the observed flow, we employ the quantile regression method to study the trends of model-simulated quantities including:

Table 3 Calibration (1995-2000) and validation (2001-2003) of the SWAT model

\begin{tabular}{|c|c|c|c|c|c|c|}
\hline \multirow[t]{2}{*}{ Station No. } & \multicolumn{3}{|c|}{ Calibration } & \multicolumn{3}{|c|}{ Validation } \\
\hline & NSE & $\mathrm{R}^{2}$ & PBIAS & NSE & $\mathrm{R}^{2}$ & PBIAS \\
\hline 1 & 0.93 & 0.95 & -1.60 & 0.92 & 0.93 & -0.10 \\
\hline 2 & 0.82 & 0.82 & -3.50 & 0.79 & 0.80 & -4.90 \\
\hline 3 & 0.78 & 0.80 & -7.70 & 0.70 & 0.73 & -18.00 \\
\hline 4 & 0.74 & 0.75 & -7.90 & 0.71 & 0.73 & -11.20 \\
\hline 5 & 0.62 & 0.63 & 0.1 & 0.42 & 0.44 & 3.70 \\
\hline 6 & 0.66 & 0.70 & 10.90 & 0.68 & 0.72 & 8.70 \\
\hline 7 & 0.72 & 0.73 & -9.9 & 0.65 & 0.66 & -9.9 \\
\hline 8 & 0.76 & 0.79 & 16.4 & 0.75 & 0.77 & 8.3 \\
\hline
\end{tabular}


- Observed flow (m3/sec) - Simulated flow (m3/sec)

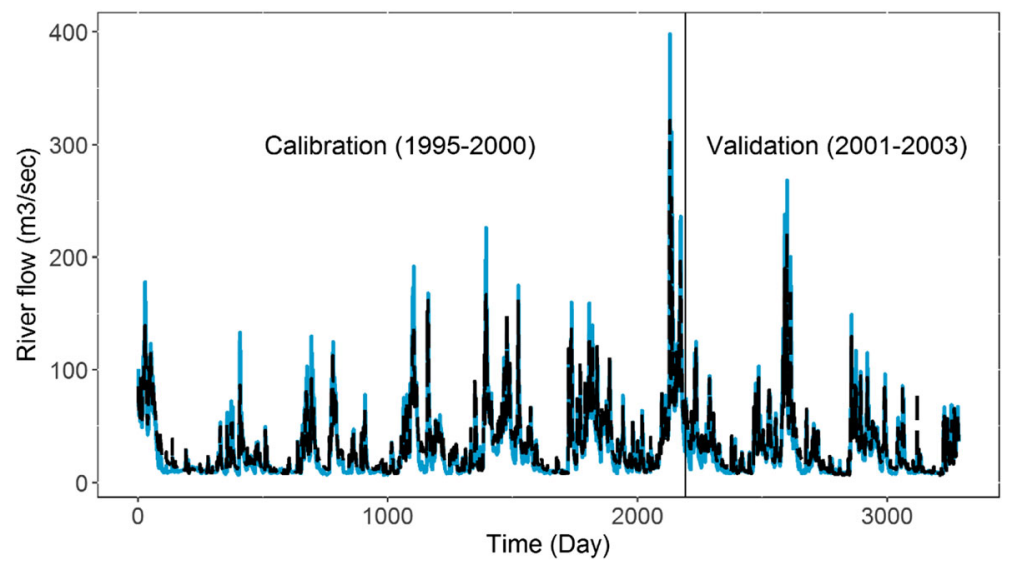

Fig. 8 Model performance at Manley Hall over both the calibration and the validation periods

(1) River discharges at the outlets of sub-basins.

(2) Water yield of the sub-catchments which is defined as the water quantity that departs the sub-basin and contributes the river flow during the time step (Arnold et al. 2013).

One must ensure that the trends produced from the simulated data be close enough to those of the corresponding observed data, just like what is done for model performance checking before the simulated data are used. The comparisons between the two types of trends (of observed and simulated river flows) are conducted at the Pont-y-Capel gauge station which has long enough records. As seen in Fig. 9, both trends are shown to be close with their largely overlapped uncertainty bands. Two quantiles, 0.05 , and 0.95 are used to fit the trends of water yield from each sub-basin. The same quantiles are also implemented to analyse the river flow at the outlets of sub-basins for both scenarios. This process is followed by a comparison of the trends of the river flow in the central reach to quantify the impact of reservoir regulations.

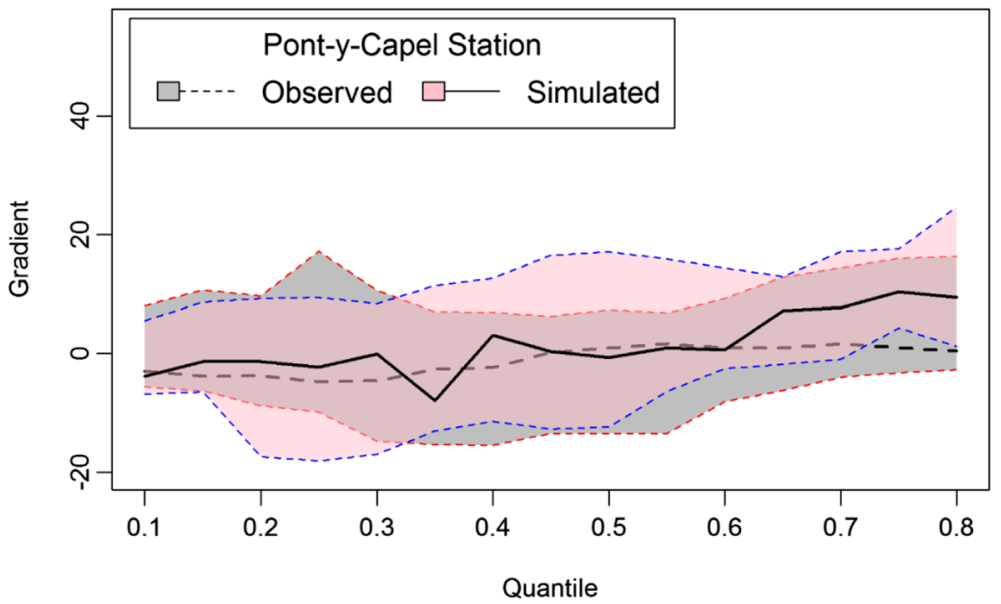

Fig. 9 Prediction bounds of the observed and simulated river flow trends at the station of Pont-y-Capel 
The water yields from all sub-basins are also analysed. The simulated daily flows and water yields are firstly aggregated into yearly value before being fitted with a linear quantile regression model with two quantiles 0.05 and 0.95 respectively. The 0.95 quantile shows a basin-wide positive trend with a range of 1.71-11.68 mm/year as illustrated in Fig. 10. Most trends are statistically significant at a significance level of 0.05 .

In comparison, the 0.05 quantile shows a mixed picture where negative trends are mainly observed in the downstream part of the river basin with a range of (-4.44)- $(-0.29) \mathrm{mm} / \mathrm{year}$; whereas the upper stream part comes with a range of $0.76-5.06 \mathrm{~mm} /$ year positive trends as shown in Fig. 11. Unlike the trends of 0.95 quantile, in most sub-basins, the trends of 0.05 quantile are not statistically significant.

For the simulated discharge (river flow) at the outlets along the minor branches and mainstream, trends of 0.05 and 0.95 quantiles are studied under both the managed and the natural scenarios. For both scenarios, the trends of 0.95 quantile are all positive with a range of $0.03-15.45 \mathrm{Mm}^{3} /$ year for the highly-managed scenario as illustrated in Figs. 12 and $0.03-$ $17.4 \mathrm{Mm}^{3} /$ year for the natural scenario.

Again, at 0.05 quantile the results are more variable with negative values mostly found in the downstream and positive trend values mainly appearing in the upstream region of the river basin. The ranges of trend values are -2.11 to $0.74 \mathrm{Mm}^{3} /$ year for the 'real-life' scenario (Fig. 13) and -2.84 to $1.89 \mathrm{Mm}^{3} /$ year for natural flow scenario.

The impact of flow control (river basin management) can be readily appreciated from Figs. 14 and 15 . The management practices significantly affect the trends of both high ( 0.95 quantile) and low flow (0.05). For 0.95 quantile, the positive trends are less in the managed scenario. For 0.05 quantile (low flow condition), the management practices are shown to have clearly mitigated the

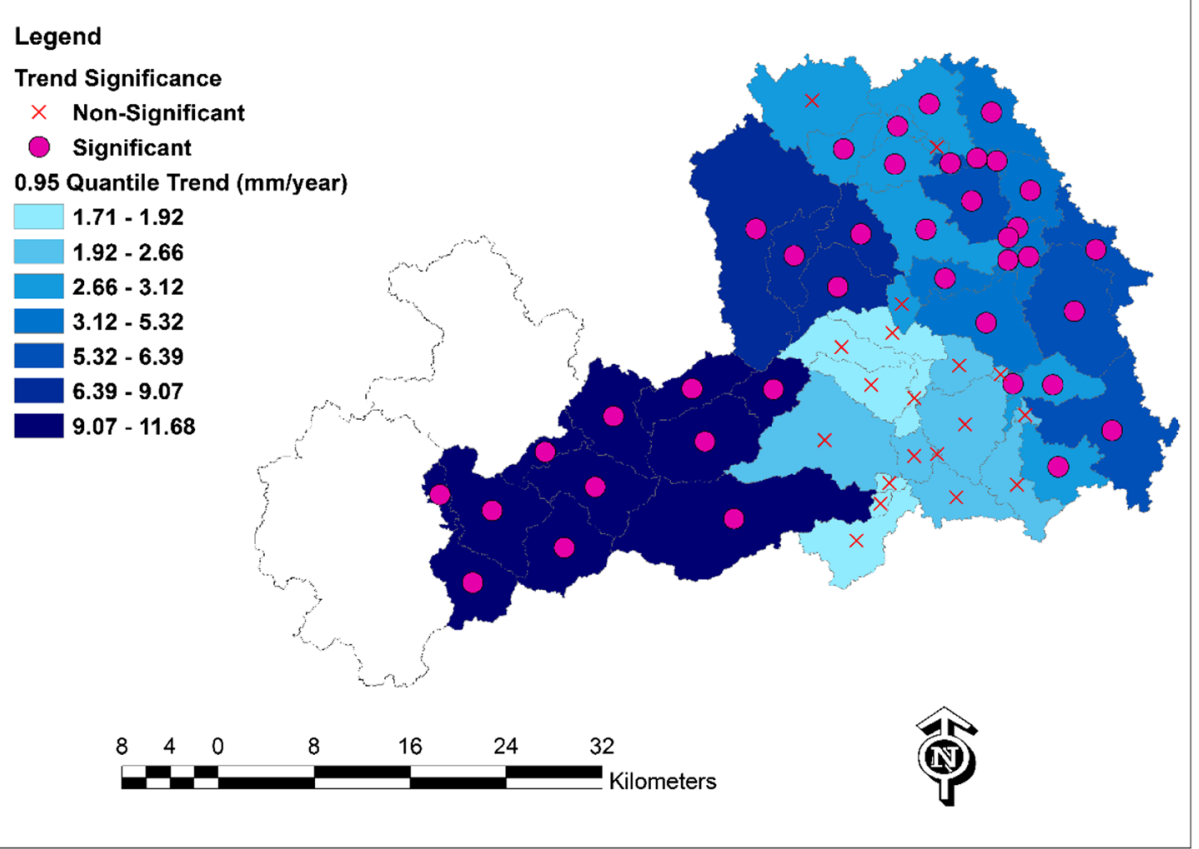

Fig. 10 Spatial distribution of the water yields trends at 0.95 quantile 


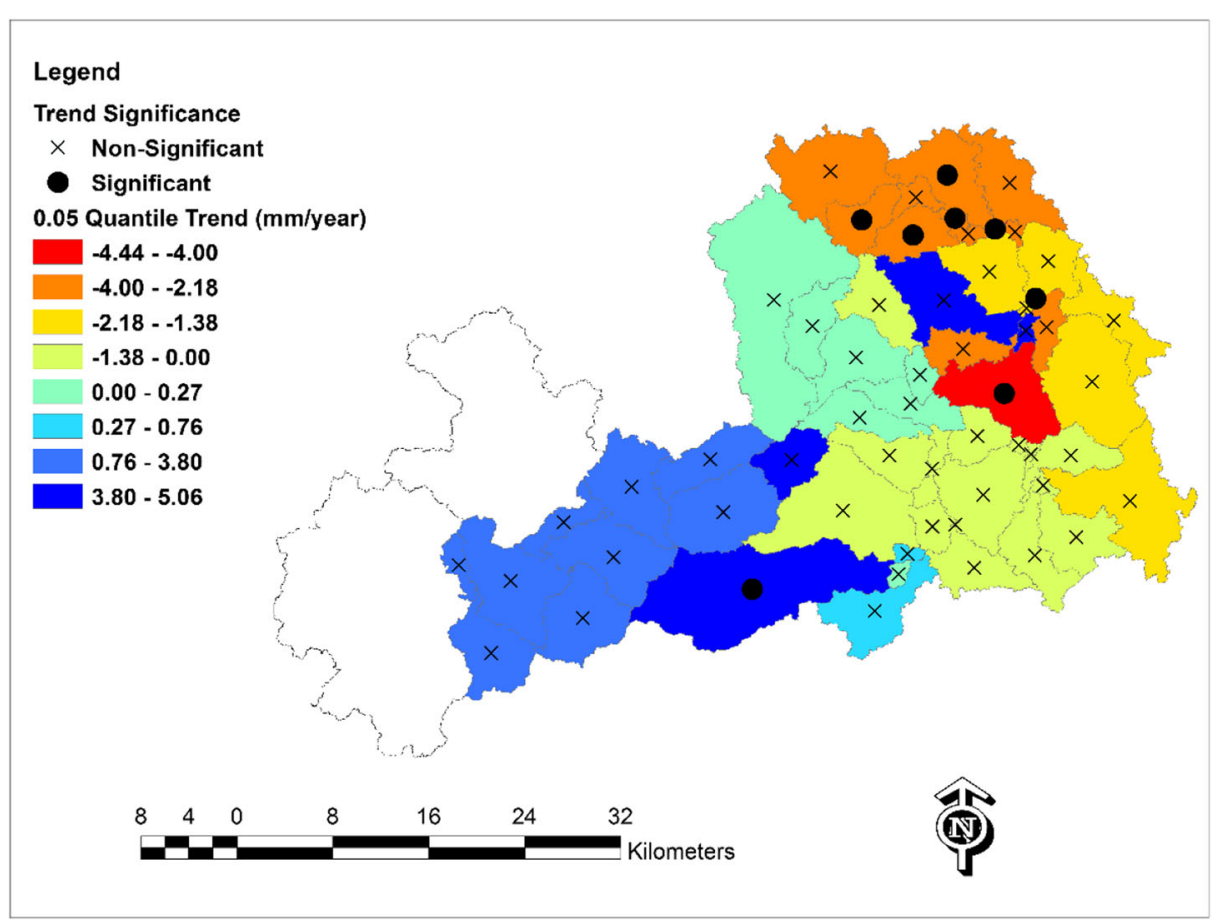

Fig. 11 Spatial distribution of the water yields trends at 0.05 Quantile

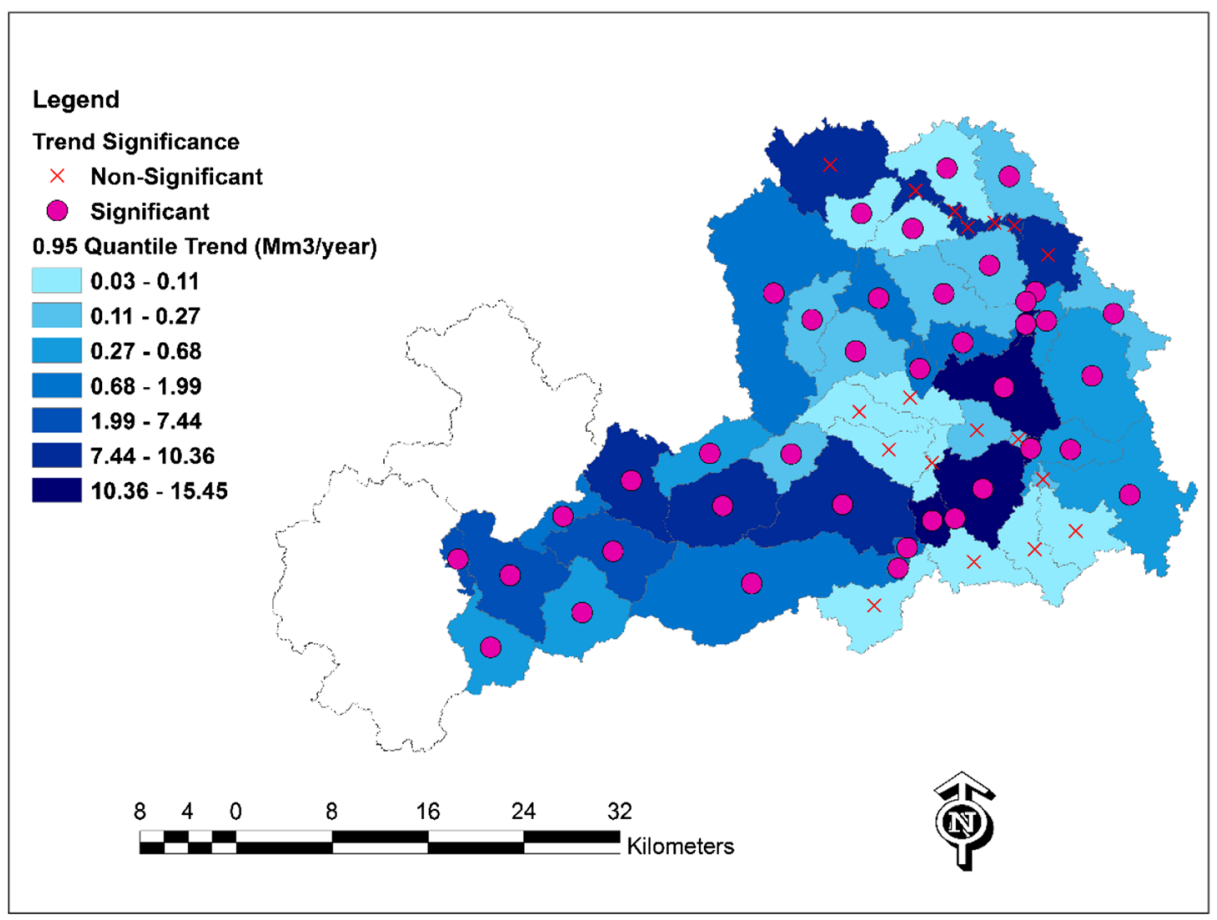

Fig. 12 Spatial distribution of the river flow trends at 0.95 Quantile for the highly managed watershed scenario 


\section{Legend}

Trend Significance

$\times$ Non-Significant

- Significant

0.05 Quantile Trend (Mm3/year)

$-2.11--1.83$

$-1.83--1.07$

$-1.07--0.38$

$-0.38-0.00$

$0.00-0.04$

$0.04-0.23$

$0.23-0.58$

$0.58-0.74$

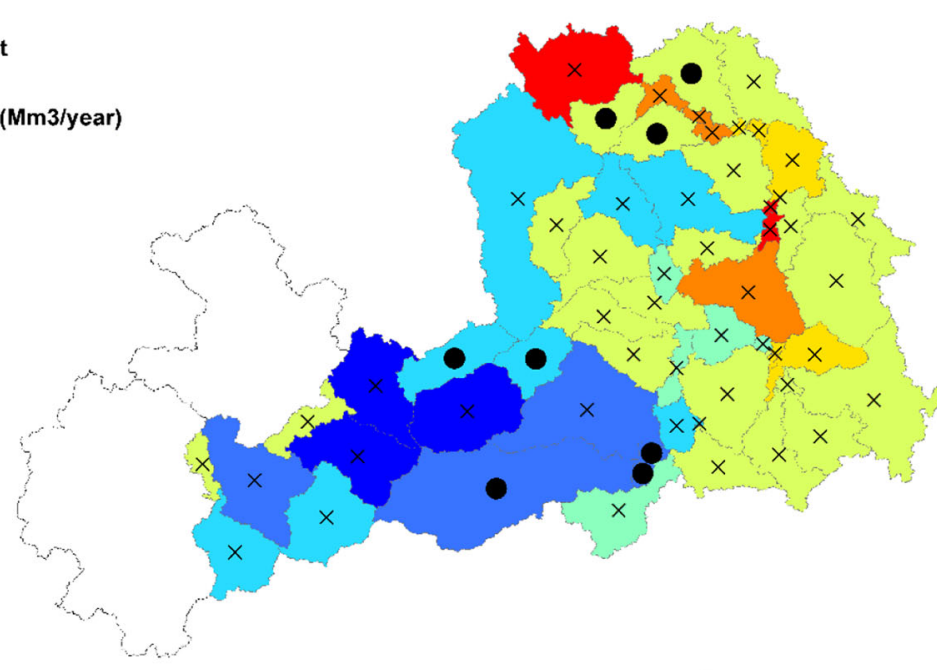

840

16

24

Kilometers

Fig. 13 Spatial distribution of the river flow trends at 0.05 quantile for the highly managed watershed scenario

Scenario.I Scenario.II

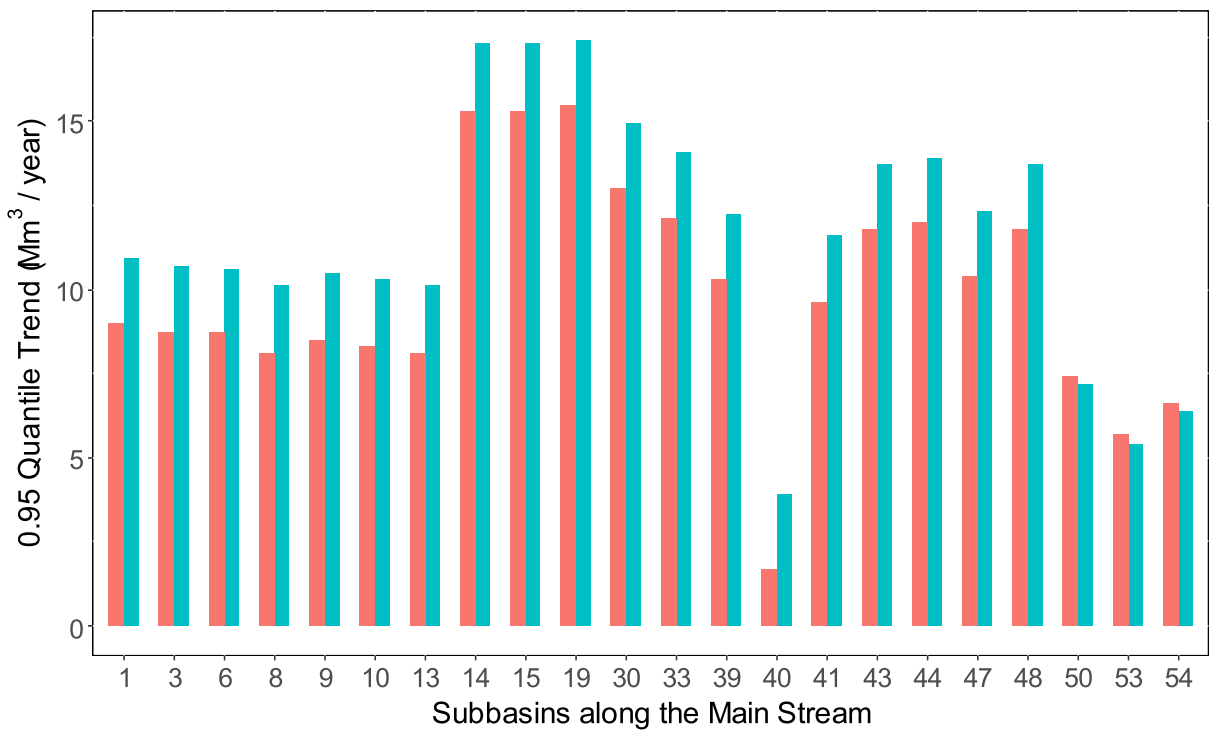

Fig. 14 Comparison of the river flow trends of the sub-basins along the main stream under Scenario I (highly regulated) and Scenario II (natural state) at 0.95 quantile 


\section{Scenario.I Scenario.II}

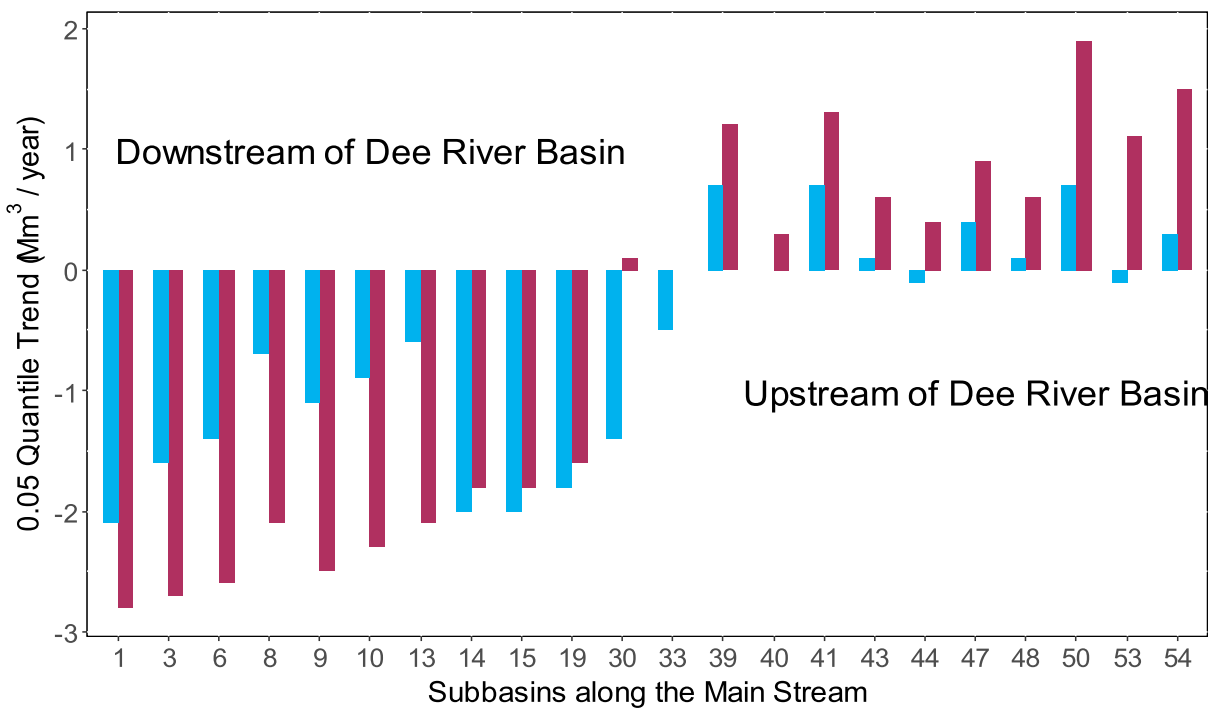

Fig. 15 Comparison of the river flow trends of the sub-basins along the main stream under Scenario I (highlyregulated) and Scenario II (natural-state) at 0.05 quantile

strong negative trends in the downstream areas as compared with the natural scenario. Since the same water-withdraw amounts are applied in both scenarios, the mitigation is shown to have effectively reduced the pressure on water supply. Such an impact is also reflected in the upper stream where the management practices have reduced the positive trend as well (Fig. 15).

\section{Conclusion}

In the present paper, we demonstrate a quantile regression-based method to study long-term trends of river flow and catchment water yields under the influence of water resources management practice. In comparison with the commonly used linear regression method, the following can be concluded:

1) This new approach excels in presenting distributed, spatially focused trend information for extremely dry and wet scenarios, which can well address the needs of practitioners and decision makers in dealing with long-term planning and climate change;

2) It can provide far more detailed trend information including abnormal situations such as dry and wet conditions, which is particularly beneficial to water managers who are concerned with extreme values rather than the average one;

3) The method shows an effective way of representing the management practice in the modelling process, which helps reveal the impact induced, and as such lays a foundation for further study on how various management practice can mitigate the impact from other sources such as climate change on catchment water resources management; and

4) The involvement of quantile regression brings an extra benefit to bridge the trend analysis with frequency, which implies great potential of its use in studying climate change impact on engineering design without being constrained by assumptions of data stationarity. 
Certainly, more studies are needed to improve the method with respect to the problems found in this study, which include but are not limited to:

1. A better link between quantiles and event frequency (return period) in the context of trend analysis; and

2. The method needs to be refined further to be more reliable on lower quantiles as the lower end of the data suffer from larger errors and zero values may as well interfere with the process.

Acknowledgements One of the co-authors, Salam A. Abbas is supported by the scholarship provided by the Higher Committee for Education Development in Iraq, for which we are grateful. We also thank Natural Resource Wales, Centre for Ecology and Hydrology/ UK and British Atmospheric Data Centre for their assistance with data collection.

\section{Compliance with Ethical Standards}

Conflict of Interest We declare that there is no conflict of interest associated with this manuscript.

Open Access This article is distributed under the terms of the Creative Commons Attribution 4.0 International License (http://creativecommons.org/licenses/by/4.0/), which permits unrestricted use, distribution, and reproduction in any medium, provided you give appropriate credit to the original author(s) and the source, provide a link to the Creative Commons license, and indicate if changes were made.

\section{References}

Abbaspour K, Faramarzi M, Ghasemi S, Yang H (2009) Assessing the impact of climate change on water resources in Iran. Water Resour Res 45(10):1-16. https://doi.org/10.1029/2008WR007615

Abbaspour K, Johnson C, van Genuchten M (2004) Estimating uncertain flow and transport parameters using a sequential uncertainty fitting procedure. Vadose Zone J 3(4):1340-1352. https://doi.org/10.2136 /vzj2004.1340

Abbaspour K, Yang J, Maximov I, Siber R, Bogner K, Mieleitner J, Zobrist J, Srinivasan R (2007) Modelling hydrology and water quality in the pre-alpine/alpine Thur watershed using SWAT. J Hydrol 333(2-4):413430. https://doi.org/10.1016/j.jhydrol.2006.09.014

Arnell NW (2004) Climate change and global water resources: SRES emissions and socio-economic scenarios. Glob Environ Chang 14(1):31-52. https://doi.org/10.1016/j.gloenvcha.2003.10.006

Arnold JG, Kiniry JR, Srinivasan R, Williams JR, Haney EB, Neitsch SL (2013) Soil and water assessment tool: input/output documentation. Version 2012. Texas Water Resources Institute. TR-439, 650

Arnold J, Srinivasan R, Muttiah R, Williams J (1998) Large area hydrologic modelling and assessment part I: model development. J Am Water Resour Assoc 34(1):73-89. https://doi.org/10.1111/j.1752-1688.1998. tb05961.x

BADC (2015) Met Office - MIDAS Land Surface Stations data. Unpublished raw data. Retrieved from http://browse.ceda.ac.uk/browse/badc

Bailey RT, Wible TC, Arabi M, Records RM, Ditty J (2016) Assessing regional-scale spatio-temporal patterns of groundwater-surface water interactions using a coupled SWAT-MODFLOW model. Hydrological Processes, 30: 4420-4433. https://doi.org/ 10.1002/hyp.10933

Breidt J (2005) Nonlinear time series: nonparametric and parametric methods. J Am Stat Assoc 100(469):348349 
Cannon A, Sobie S, Murdock T (2015) Bias correction of GCM precipitation by quantile mapping: how well do methods preserve changes in quantiles and extremes? J Clim 28(17):6938-6959. https://doi.org/10.1175/jclid-14-00754.1

DEFRA (2014) The Impact of Water Abstraction Reform: Public Water Supply Operations. Wallingford: Department for Environment, Food and Rural Affairs/ flood risk management division

Dutta D, Kim S, Vaze J, Hughes J (2015) Streamflow predictions in Regulated River systems: hydrological nonstationarity versus anthropogenic water use. Proc Int Assoc Hydrol Sci 371:35-42. https://doi.org/10.5194 /piahs-371-35-2015

Ficklin D, Stewart I, Maurer E (2013) Climate change impacts on stream flow and subbasin-scale hydrology in the upper Colorado River basin. PLoS One 8(8):e71297. https://doi.org/10.1371/journal.pone.0071297

Gringorten I (1963) A plotting rule for extreme probability paper. J Geophys Res 68(3):813-814. https://oi. org/10.1029/jz068i003p00813

Haddeland I, Skaugen T, Lettenmaier DP (2007) Hydrologic effects of land and water management in North America and Asia: 1700-1992. Hydrol Earth Syst Sci Discuss 11(2):1035-1045

Kendall MG (1975) Rank auto-correlation methods. Charles Griffin, London

Koenker R (2005) Quantile Regression (No. 38). Cambridge university press

Koenker R, Bassett G (1978) Regression Quantiles. Econometrica 46(1):33. https://doi.org/10.2307/1913643

Koenker R, Portnoy S, Ng PT, Zeileis A, Grosjean P, Ripley BD (2016) Package 'quantreg'

Kubilius K, Melichov D (2008) On estimation of the Hurst index of solutions of stochastic integral equations. Liet Mat Rink 48(49):401-406

Luce C, Holden Z (2009) Declining annual streamflow distributions in the Pacific Northwest United States, 1948-2006. Geophys Res Lett 36(16). https://doi.org/10.1029/2009g1039407

Mann H (1945) Nonparametric tests against trend. Econometrica, 13(3):245-259. https://doi.org/10.2307 $/ 1907187$

Mayall S (2000) Management of the river Dee system: the 1995/96 drought experience. BHS. Occas Pap 11:125132

Mazvimavi D (2010) Investigating changes over time of annual rainfall in Zimbabwe. Hydrol Earth Syst Sci 14(12):2671-2679. https://doi.org/10.5194/hess-14-2671-2010

McKenzie A (2015) User guide for the British Geological Survey National Depth to Groundwater Dataset. Nottingham, UK, British Geological Survey, 16pp. (OR/15/006) (unpublished)

Miao C, Su L, Sun Q, Duan Q (2016) A nonstationary Bias-correction technique to remove Bias in GCM simulations. J Geophys Res: Atmos 121(10):5718-5735. https://doi.org/10.1002/2015jd024159

Modarres R, Sarhadi A (2009) Rainfall trends analysis of Iran in the last half of the twentieth century. J Geophys Res: Atmos 114(D3):1-9

Natural Resources Wales and Environmental Agency (2014) Dee River Basin District Consultation on the draft Flood Risk Management Plan (pp. 1-65). Cardiff

Neitsch SL,Arnold JG,Kiniry JR,Williams JR (2011) Soil and Water Assessment Tool: Theoretical Documentation Version 2009, Texas Water Resources Institute Technical Report No. 406, Texas A\&M University System, Texas, USA

Piao S, Friedlingstein P, Ciais P, de Noblet-Ducoudré N, Labat D, Zaehle S (2007) Changes in climate and land use have a larger direct impact than rising $\mathrm{CO}_{2}$ on Global River runoff trends. Proc Natl Acad Sci 104(39): 15242-15247. https://doi.org/10.1073/pnas.0707213104

Sayemuzzaman M, Jha M (2014) Seasonal and annual precipitation time series trend analysis in North Carolina, United States. Atmos Res 137:183-194

Schneider C, Laizé CLR, Acreman MC, Florke M (2013) How will climate change Modify River flow regimes in Europe? Hydrol Earth Syst Sci 17(1):325-339. https://doi.org/10.5194/hess-17-325-2013

Siebert S, Burke J, Faures JM, Frenken K, Hoogeveen J, Döll P, Portmann FT (2010) Groundwater use for irrigation-a global inventory. Hydrol Earth Syst Sci 14(10):1863-1880

Singh J, Knapp HV, Arnold JG, Demissie M (2005) Hydrological modeling of the Iroquois River watershed using HSPF and SWAT 1. J Am Water Resour Assoc 41(2):343-360

Solomon, S. (Ed.). (2007). Climate Change 2007-the Physical Science Basis: Working group I contribution to the fourth assessment report of the IPCC (Vol. 4). Cambridge University press

Sonali P, Kumar DN (2013) Review of trend detection methods and their application to detect temperature changes in India. J Hydrol 476:212-227

Song X, Zhang J, AghaKouchak A, Roy S, Xuan Y, Wang G et al (2014) Rapid urbanization and changes in spatiotemporal characteristics of precipitation in Beijing metropolitan area. J Geophys Res: Atmos 119(19): 11,250-11,271. https://doi.org/10.1002/2014jd022084

Tabari H, Somee BS, Zadeh MR (2011) Testing for long-term trends in climatic variables in Iran. Atmos Res 100(1):132-140 
Tareghian R, Rasmussen P (2013) Statistical downscaling of precipitation using quantile regression. J Hydrol 487:122-135. https://doi.org/10.1016/j.jhydrol.2013.02.029

Vicente-Serrano S, Zabalza-Martínez J, Borràs G, López-Moreno JI, Pla E, Pascual D, Savé R, Biel C, Funes I, Martín-Hernández N (2017) Effect of reservoirs on streamflow and river regimes in a heavily regulated river basin of Northeast Spain. Catena 149:727-741

Villarini G, Smith J, Napolitano F, Baeck M (2011) Hydro-meteorological analysis of the December 2008 flood in Rome. Hydrol Sci J 56(7):1150-1165. https://doi.org/10.1080/02626667.2011.608678

Wada Y, Bierkens MF, De Roo A, Dirmeyer PA, Famiglietti JS, Hanasaki N, Konar M, Liu J, Schmied HM, Oki T (2017) Human-water interface in hydrological modelling: current status and future directions. Hydrol Earth Syst Sci 21(8):4169-4193

Weerts A, Winsemius H, Verkade J (2010) Estimation of predictive hydrological uncertainty using quantile regression: examples from the National Flood Forecasting System (England and Wales). Hydrol Earth Syst Sci Discuss 7(4):5547-5575. https://doi.org/10.5194/hessd-7-5547-2010

Yang Q, Tian H, Li X, Tao B, Ren W, Chen G, Lu C, Yang J, Pan S, Banger K (2014) Spatiotemporal patterns of evapotranspiration along the north American east coast as influenced by multiple environmental changes. Ecohydrology 8(4):714-725

Yoon Y, Beighley E, Lee H, Pavelsky T, Allen G (2016) Estimating flood discharges in reservoir-Regulated River basins by integrating synthetic SWOT satellite observations and hydrologic modelling. J Hydrol Eng 21(4): 05015030. https://doi.org/10.1061/(asce)he.1943-5584.0001320

Zang C, Liu J (2013) Trend analysis for the flows of green and blue water in the Heihe River basin, northwestern China. J Hydrol 502:27-36

Zhao A, Zhu X, Liu X, Pan Y, Zuo D (2016) Impacts of land use change and climate variability on green and blue water resources in the Weihe River basin of Northwest China. Catena 137:318-327

Publisher's Note Springer Nature remains neutral with regard to jurisdictional claims in published maps and institutional affiliations. 